
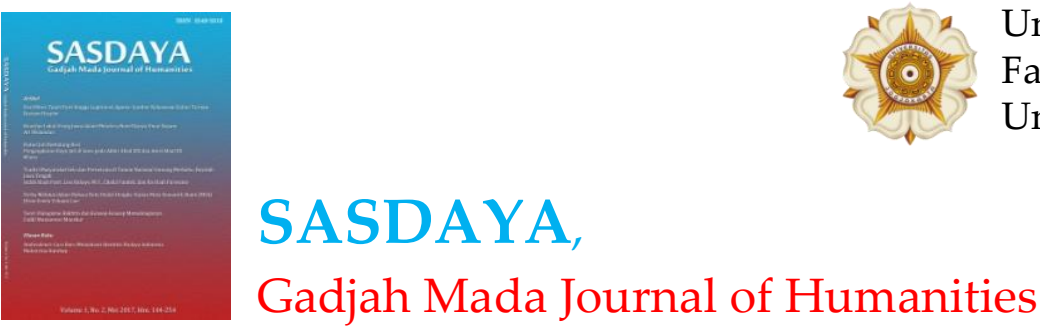

ISSN: 2548-3218 (print); ISSN : 2549-3884 (online); website: https://jurnal.ugm.ac.id/sasdayajournal

Dari Mitos Tujuh Putri hingga Legitimasi Agama: Sumber Kekuasaan Sultan Ternate

From the Myth Seven Daughters to the Legitimacy of Religion: the Source of Powers of the Ternate Sultans

Penulis/Author(s): RUSTAM HASYIM

Sumber/Source :SASDAYA, Gadjah Mada Journal of Humanities, Vol. 1, No. 2 (May 2017), pp. 144-163

- Penerbit : Unit Penelitian dan Publikasi Fakultas Ilmu Budaya

Universitas Gadjah Mada, Indonesia

Redaksi

Program Pascasarjana

Fakultas Ilmu Budaya Universitas Gadjah Mada

Jl. Nusantara, No. 1, Bulaksumur Yogyakarta. E-mail: sasdayajournal.fib@ugm.ac.id 


\section{DAFTAR ISI}

\section{Artikel}

Dari Mitos Tujuh Putri hingga Legitimasi Agama:

Sumber Kekuasaan Sultan Ternate

Rustam Hasyim

Kearifan Lokal Orang Jawa dalam Metafora Novel Para Priyayi

Karya Umar Kayam

Ari Wulandari.

Hutan Jati Berkalung Besi: Pengangkutan Kayu Jati

di Jawa pada Akhir Abad Ke-19 dan Awal Abad ke-20

Warto

Tradisi Masyarakat Selo dan Pariwisata di Taman Nasional Gunung Merbabu, Boyolali Jawa Tengah

Indah Riadi Putri, Lies Rahayu Wijayanti Faida,

Chafid Fandeli, dan Ris Hadi Purwanto

Verba Melukai dalam Bahasa Rote Dialek Dengka: Kajian Meta Semantik Alami (MSA)

Efron Erwin Yohanis Loe

Teori Dialogisme Bakhtin dan Konsep-Konsep Metodologisnya

Fadlil Munawwar Manshur 235

\section{Ulasan Buku}

Ambivalensi: Cara Baru Memahami Identitas Budaya Indonesia

Muharrina Harahap 


\title{
DARI MITOS TUJUH PUTRI HINGGA LEGITIMASI AGAMA: SUMBER KEKUASAAN SULTAN TERNATE
}

\author{
Rustam Hasyim ${ }^{1}$
}

\begin{abstract}
Noble people from circle of Sultanate of Ternate construct and maintain their power base by creating the magical aspect of religious and Culture. This hegemonic strategy allowed this group to pose a certain powerful position and to have a certain place in the heart of the people of Ternate. There are, at least, four important heritage elements in the Sultanate of Ternate used as a strategy to form and strengthen their position. The first is the doctrine Jou se Ngofangare (king and servant) which means Sultan as the representation of God's power (macro cosmos). Second is the mythical Seven Princess, which justifies the Sultan position by using magical-religious as a means to gain people consent. Third, this group tends to use their noble title and heirloom as signs of charisma and sacred magical power. Those heirlooms such as sword and title function to legitimize the Sultan as ruler. Fourth, Kadaton (palace) which produces cultural meaning as the highest indigenous identity and the source of magical belief.
\end{abstract}

Keywords: Ternate, castles, sultan, politics, cultural legitimation.

\section{Pengantar}

Kemunculan kembali entitas politik masa lalu di tingkat lokal pada saat ini, dapat dipahami sebagai proses transisi politik yang berlangsung sejak berakhirnya rezim Orde Baru pada 1998. ${ }^{2}$ Proses politik tersebut, berimplikasi pada pergeseran tata hubungan kekuasan antara institusi politik pusat dengan daerah. Pergeseran politik itu berjalan beriringan dengan menurunnya kredibilitas negara dan institusinya. Keadaan itu dijadikan momentum oleh kekuatan-kekuatan lama, termasuk kekuasaan feodalistik di daerah, untuk bangkit kembali memperjuangkan hak-hak politik di wilayah kekuasaannya dalam ranah politik lokal.

Menurut Ari Dwipayana (2004), sebelum kemerdekaan terdapat sekitar 250 daerah swapraja atau zelbestuurendelandschappen dalam teritori Indonesia. Sebagian

${ }^{1}$ Dosen pada Program Studi Pendidikan Pancasia dan Kewarganegaraan, Universitas Khairun Ternate.

${ }^{2}$ AAG. Ari Dwipayana, Bangsawan dan Kuasa Kembalinya Para Ningrat di Dua Kota. (Yogyakarta, IRE Press, 2004), hlm. 7. 
besar dari daerah swapraja tersebut sama sekali tidak meninggalkan artefak atau bukti-bukti sejarah. Namun ada beberapa di antaranya yang masih eksis secara politik hingga sekarang seperti: Daerah Istimewa Yogyakarta, Kasuhunan Surakarta, Kesultanan Cirebon, Kesultanan Tidore dan Kesultanan Ternate. Bahkan beberapa keraton dapat dibangun dan tradisinya dihidupkan kembali serta menjalin kerjasama dalam Aliansi Keraton-keraton Nusantara. ${ }^{3}$

Salah satu kekuasaan tradisional yang tetap hidup hingga kini adalah Kesultanan Ternate. Keberadaan Sultan Ternate terus berlangsung karena posisi politik sebagai pusat panutan di tengah-tengah kehidupan masyarakat telah menjadi tradisi di dalam masyarakat Ternate. Kedudukan sultan yang strategis dalam kehidupan masyarakat Ternate menimbulkan kepercayaan bahwa sultan dan istana, bukan saja sebagai pusat politik dan kebudayaan tetapi juga sebagai pusat magisreligius kerajaan. Status sultan sebagai Tubaddilur rasul, melahirkan suatu kepercayaan bahwa para sultan dianggap memiliki kekuatan magis yang dapat memberi perlindungan, keselamatan dan kesejahteraan bagi semua rakyatnya. Semua itu terlukis dalam berbagai doa keselamatan, doa kololi kie (mengelilingi gunung), doa fere kiye (naik gunung) dan doa upacara pelantikan sultan. Orang Ternate menyadari bahwa otoritas kharismatik dengan latar belakang agama yang dimiliki para sultan dipengaruhi oleh konsepsi mitologis. Konsep ini dilukiskan dalam suatu kepercayaan bahwa para sultan dianggap memiliki kekuatan magis dan kosmologis. Basis kekuasaan melalui rekayasa dari segi magis keagamaan dan kebudayaan ini adalah sebuah strategi hegemonik yang kemudian membuat kelompok ini tampil menjadi penguasa dan pusat panutan dalam kehidupan masyarakat Ternate. Lebih dari itu, konsepsi magis dan mitologis ini dijadikan pembenaran bahwa sumber kewenangan/kekuasaan yang diperoleh para Sultan Ternate dalam memerintah berasal dari sumber yang diangggap suci, yakni Tuhan. Kepercayaan dan agama menguasai masyarakat Ternate dan kedudukan sultan dalam masyarakat memperoleh dukungan yang kuat dari keyakinan agama. Alasan inilah yang membentuk pemikiran bahwa hanya orang-orang anggota keturunan sultanlah yang mempunyai hak untuk tetap berkuasa. Legitimasi magis-religius tersebut menyebabkan istana bukan semata-mata tempat tinggal sultan dan kerabatnya, melainkan juga dipandang sebagai negara itu sendiri. Dengan demikian, sultan dan istananya merupakan kesatuan integral yang saling menguatkan. Seorang sultan tidak akan mempunyai arti secara politis kalau tidak dikokohkan oleh istana. Sultan yang tidak memiliki istana akan mengalami kemerosotan status sosial, yang dalam bahasa Clifford Geertz (1981) menyebutnya sebagai status yang menurun. ${ }^{4}$

\footnotetext{
3 Setelah kemerdekaan dan pasca-Orde Baru, beberapa keraton bekas swapraja mulai memiliki peran signifikan dalam politik lokal. Kemunculan entitas politik masa lalu tersebut, baik yang sudah eksis maupun yang baru muncul belakangan telah bergabung dalam suatu forum Aliansi Keraton-keraton Nusantara. Sekarang sudah terhitung kesepuluh kali mengelar Festival Keraton Nusantara (FKN), bahkan FKN X yang telah dilaksanakan di Solo 2010 dihadiri sekitar 34 peserta dari kesultanan-kesultanan di Indonesia. Ini mengalami peningkatan keanggotaan bila dibandingkan dengan festival pertama dilaksanakan di Yogyakarta yang hanya diikuti 20 peserta. Lihat AAG. Ari Dwipayana, Ibid., hlm. 8.
}

${ }^{4}$ Clifford Geertz, Abangan, Santri dan Priyayi Dalam Masyarakat Jawa, (Pustaka Jaya:1981). 
Sebaliknya, istana tidak bisa menjadi institusi penting jika tidak diperkuat oleh keterampilan politik dari bangsawan yang setiap saat dengan daya kreasi mereka dalam meningkatkan kewibawaan istana.

Tulisan ini menganalisis strategi apa saja yang digunakan oleh para Sultan Ternate dalam membangun basis kekuasaan, sehingga menyebabkannya tetap eksis hingga kini. Beberapa hal penting yang ingin dieksplorasi antara lain, bagaimana para Sultan Ternate mempertahankan kekuasaan dengan mengunakan doktrin kekuasaan, dengan memposisikan istana sebagai sumber kepercayaan magis dan legitimasi adat tertinggi untuk mendapatkan kedudukan, kekuasaan dan identitas.

\section{Mitos Tujuh Putri sebagai Sumber Legitimasi}

Konsepsi kekuasaan Kesultanan Ternate tidak terlalu berbeda dengan konsep kekuasaan raja-raja di Jawa. ${ }^{5}$ Konsep kekuasaan Kesultanan Ternate selalu menempatkan asal-usul sebagai sesuatu yang sangat penting. Hal itu membuat para sultan sangat berorentasi kepada teks babad maupun silsilah. Orientasi itu kemudian memunculkan penciptaaan mitos geneologis yang digunakan untuk legitimasi politiknya. Pembicaraan mengenai geneologis atau silsilah raja-raja (sultan) Ternate tidak dapat dipisahkan dari mitos Tujuh Putri atau yang dikenal sebagai Hikayat Ternate. Mitos itu ditulis oleh Naidah (1856-1866), seorang pujangga istana yang menjabat sebagai Hukum Soa-Sio (Mahkam Agung) Kesultanan Ternate pada masa

\footnotetext{
${ }^{5}$ Soemarsaid Moertono mengatakan konsepsi tentang kekuasaan Jawa (Dinasti Mataram) adalah menciptakan silsilah yang dimulai dari Nabi Adam sebagai manusia pertama. Karena itu, raja-raja Mataram menggambarkan diri sebagai raja yang agung dan binathara. Dalam usahanya memperoleh, menghimpun, dan mempertahangkan kekuasaanya, Raja Jawa melakukan tindakan-tindakan yang menekan hawa nafsu, misalnya berpuasa, bersamadi, bertapa, melakukan pemurnian ritual dan sebagainya. Hal senada juga dikemukakan oleh Benedict R. O'G.Anderson, bahwa konsepsi Jawa mengenai kekuasaan berdimensi empat sesuai konsepsi yang dipakai dalam pewayangan (sakti mandraguna dan mukti wibawa). Sejalan dengan itu, menurut Sartono Kartodirdjo, negara kosmis sangat erat hubungannya dengan konsep raja yang bersifat dewa, yaitu anggapan bahwa raja adalah titisan dewa. Konsep raja-dewa ini pada periode kerajaan Islam tidak menempatkan raja pada kedudukan yang sama dengan Tuhan, melainkan sebagai khalifatullah (sebagai wakil Tuhan di dunia). Begitu pula menurut Suhartono W. Pranoto yang mengatakan bahwa konsepsi orang Jawa mengenai kekuasaan sebagai kekuatan energi yang sakti dan keramat itu adalah konsepsi yang selalu dipakai raja-raja untuk mengemban misi memperkuat dinasti, sebab bilama mana usahanya berhasil, maka itu sekaligus akan dapat memperkuat kedudukannnya sendiri di dalam dinasti. Lebih jelasnya lihat Soemarsaid Moertono, Negara dan Usaha Binna Negara di Jawa Masa Lampau: Studi Tentang Mataram II Abad ke XVI Sampai XIX (Jakarta: Yayasan Obor Indonesia, 1985); Benedict R. O'G. Anderson, Kuasa-Kata: Jelajah BudayaBudaya Politik di Indonesia. (Yogyakarta: Mata Bangsa, 2000), Sartono Kartodirdjo, Kepemimpinan dalam Dimensi Sosial. (Jakarta:LP3, 1984); Suhartono W. Pranoto, Serpihan Budaya Feodal (Yogyakarta: Agastya Media, 2001), dan G. Moedjanto, Konsep kekuasaan Jawa: Penerapannya Oleh Raja-raja Mataram. (Yogyakarta: Kanisius, 1987).
} 
pemerintahan Sultan Ternate ke-41 Muhammad Arsyad (1852-1869). ${ }^{6}$ Mitos ini memberi peran sentral kepada seorang tokoh legendaris dari Arab, Jafar Shadik (terkadang disebut Jafar Nuh), yang tiba di Ternate pada hari Senin 6 Muharram 643 Hijriah atau 1250 Masehi. Jafar Shadik, yang nasabnya dihubungkan dengan Ali bin Abi Thalib, menantu Nabi Muhammad SAW, kemudian kawin dengan seorang putri bernama Nur Sifa. Naidah kemudian mengisahkan asal-usul Kerajaan Ternate seperti berikut ini:

"Syahdan, datanglah seorang Arab yang bernama Jafar Shadik. Dia membangun rumah di atas sebuah bukit yang bernama Jore-jore, dan di kaki bukit itu terdapat sebuah mata air bernama Ake Sentosa.

Pada suatu hari, sewaktu Jafar Shadik hendak mandi di mata air itu, ia melihat tujuh bidadari cantik yang tengah mandi. Jafar Shadik berkesempatan mengambil sepasang sayap milik salah satu dari bidadari itu dan menyembunyikannya. Setelah puas mandi-mandi, bersiaplah para bidadari itu pulang ke kayangan, tapi salah satu di antaranya, bernama Nur Sifa, terpaksa tinggal karena sayapnya hilang, yang akhimya kawin dengan Jafar Shadik.

Dari perkawinan mereka ini, lahirlah tiga anak laki-laki. Masing-masing diberi nama Buka, Darajat, dan Sahajat. Suatu hari, saat Nur Sifa tengah memandikan Shajat, secara kebetulan ia melihat bayangan sayapnya terpantul dari air yang digunakan untuk memandikan anaknya. Akhimya diketahuilah olehnya di mana sayap itu disimpan oleh suaminya. Segera bersiaplah ia untuk pulang, namun setiap ia hendak terbang, selalu saja si bungsu menangis. Kemudian ditampunglah air susunya untuk kemudian diberikan kepada si sulung Buka, sambil berpesan agar diberikan kepada adiknya kalau menangis dan agar memberi tahu ayahnya kalau ia sudah pulang ke tempat asalnya. Terbanglah ia kemudian meninggalkan suami dan anak-anaknya.

Demi mendengar bahwa istrinya telah pergi, menangislah Jafar Shadik. Tanpa disadari, seekor burung tengah mengamatinya. Burung Goheba (garuda berkepala dua) itu bertanya kepadanya perihal kesedihannya.

Burung Goheba terharu mendengar cerita Jafar Shadik dan menawarkan diri mengantarkan ke kayangan untuk mencari istrinya. Sesampai di sana ia bertemu dengan ayah Nur Sifa dan menanyakan perihal istrinya. Kepada Jafar Shadik kemudian dihadapkan tujuh bidadari yang ternyata sangat mirip satu sama lain, baik wajah atau perawakannya, untuk ditunjuk yang mana istrinya yang dimaksudnya. Disyaratkan pula kepadanya, kalau ia bisa menunjuk secara tepat, ia bisa membawanya pulang. Tapi kalau tidak, nyawa Jafar Shadik sendiri taruhannya.

Dalam kebimbangan itu, tiba-tiba hinggap di pundak Jafar Shadik seekor

\footnotetext{
6 Naskah yang bercerita tentang asal-usul raja-raja Maluku Utara yang ditulis Naidah dengan mengunakan Bahasa Ternate. Naskah tersebut hingga kini tersimpan di kadaton Ternate dan disebut "Buku Tembaga." Pada masa Residen Ternate, P. van der Crab (18631864), naskah tersebut diterjemahkan ke dalam bahasa Belanda dan diterbitkan tahun 1879 dengan judul, Bijdragen tot de Taal-Land en Volkenkunde van Nederlandsch Indie (BKI) dengan judul Geschiedenis van Ternate, in Ternataansche en Maleische Teks, Beschreven Door den Ternataan Naidah, Met Vertaling en Aantekeninghen Door. P. van der Crab.
} 
lalat hijau (gufu sang). Lalat itu menawarkan jasanya sambil meminta imbalan. Kepada lalat hijau itu Jafar Shadik menjanjikan semua yang berbau busuk di muka bumi ini untuknya, dan tawaran itu disepakati oleh sang lalat. Dengan mudah akhimya lalat itu dapat mengenali Nur Sifa hanya dari bau badannya yang berbeda dari bidadari lainnya karena baunya yang khas sebagai seorang wanita yang tengah menyusui. Atas bantuan lalat itulah akhirnya Jafar Shadik dapat mengenali istrinya, Nur Sifa.

Jafar Shadik akhirnya diterima sebagai anggota keluarga penuh dan perkawinannya dengan Nur Sifa mendapat restu dari sang Ayah. Selama tinggal di kayangan, mereka mendapatkan putra ke empat, yang kemudian mereka beri nama Mashur Malamo. Setelah Malamo genap berusia setahun, mereka berpamit untuk kembali ke bumi. Tapi rencana itu selalu tertunda garagara Malamo selalu menangis setiap hendak berangkat. Mansur Malamo baru diam setelah oleh kakeknya memberinya tolu (mahkota) yang tengah dikenakannya. Segeralah mereka bertiga kembali ke Bumi.

Setiba di Bumi mereka bertemu kembali dengan ketiga anaknya yang ditinggalkan sekian lama. Kemudian kepada ke empat anaknya itu Nur Sifa memberinya tanda-tanda pengukuhan kedudukan mereka dalam hal pembagian kekuasaan. Kepada anak pertama, namanya Buka, diberinya age (kayu) sebagai tempat duduknya. Buka kemudian segera berangkat menuju Makian dan menjadi cikal-bakal kolano (raja) dan diberi gelar Dehe Ma Kolano (penguasa tanjung). Anak kedua, Darajat, mendapat kayu ginoti, dan kelak menjadi cikal-bakal kolano (raja) Jailolo dan diberi gelar Jiko Makolano (penguasa teluk). Sahajat, anak ketiga, mendapatkan tempat duduk dari batu dan menjadi cikal-bakal kolano (raja) Tidore dan diberi gelar Kie Ma Kolano (penguasa gunung). Sementara Mashur Malamo, si bungsu, mendapatkan sebuah kursi dan menjadi cikal-bakal kolano (raja) Ternate dan diberi gelar Alam Ma Kolano (penguasa dunia) dan Kolano Maluku (penguasa Maluku)."7

Silsilah sebagaimana ditunjukan (bagan 1) memperlihatkan bahwa keturunan sultan-sultan Ternate adalah keturunan tokoh-tokoh luar biasa. Kelompok pertama (pihak laki-laki) adalah keturunan nabi dan kelompok kedua (pihak ibu) adalah keturunan raja kayangan atau dewa. Maka memenuhi syaratlah kalau dinasti ini menjadi penguasa kerajaan. Nadiah seolah hendak menunjukkan kesan politis bahwa Jafar Shadik merupakan leluhur dari raja-raja yang berkuasa di Maluku Utara, sedangkan Masyhur Malamo yang dilahirkan di kayangan merupakan cikalbakal sultan-sultan Ternate berikutnya dan menempati kedudukan yang utama. ${ }^{8}$

'Djoko Suryo, et al. Agama dan Perubahan Sosial Studi: Tentang Hubungan Antara Islam, Masyarakat, dan Struktur Sosial Politik Indonesia. (Yogyakata: UGM LKPSM. 2001), hlm. 115.

8 Pembentukan kerjaaan Ternate, sebagaimana dikemukakan dalam berbagai penelitan menempatkan tokoh Masyhur Malamo dari Marga Tobona sebagai cikal-bakal pembentukan kerajaan Ternate. Ia juga merupakan orang pertama yang bergelar kolano (raja). Hal tersebut juga disebutkan dalam mitos Tujuh Putri. Ini mengindikasikan bahwa sumber-sumber yang digunakan dalam menelusuri awal pembentukan kerajaan Ternate berasal dari Naidah, sebagaimana sering dijadikan rujukan oleh banyak penulis lokal maupun asing. 
Selanjutnya, ia ditetapkan sebagai raja Ternate yang pertama pada zaman kolano (kerajaan). Sementara saudara-saudaranya menjadi cakal-bakal sultan-sultan pada kerajaaan lainya di Maluku Utara yakni Kesultanan Bacan, Jailolo, dan Tidore, sekaligus pemimpin dari suatu konfederasi yang kemudian dikenal sebagai Moloku Kie Raha (Empat Kerajaan: Bacan, Jailolo, Tidore, dan Ternate).

Bagan 1. Silsilah Raja-raja Ternate

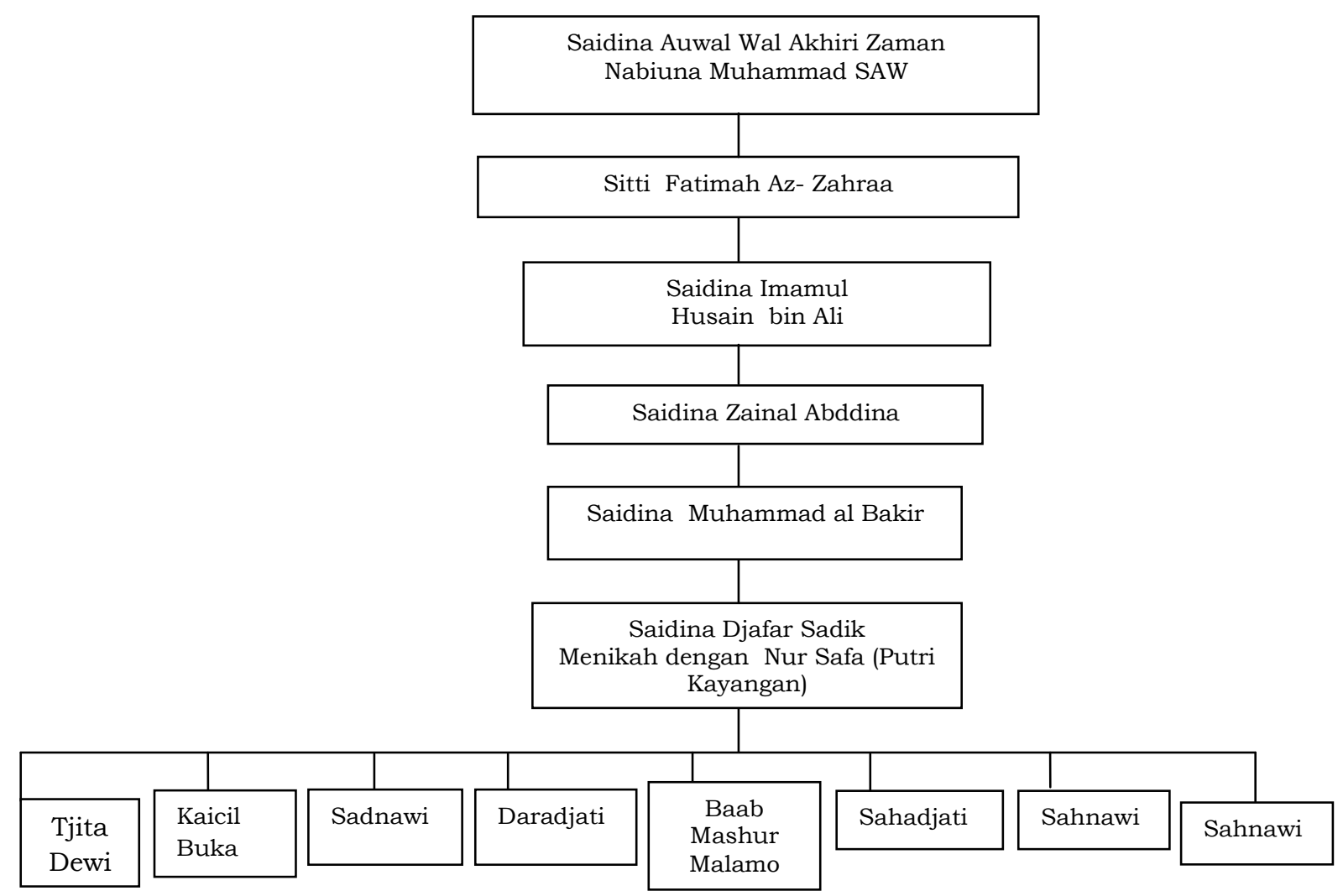

Sumber: diolah dari hasil penelitian

Sudah menjadi pengetahuan umum masyarakat Ternate bahwa kedudukan para Sultan Ternate adalah dinasti yang berasal dari keturunan para nabi, oleh karena itu dapat dikatakan berlandaskan agama (Islam). Kepercayaan orang Ternate yang masih dipengaruhi kepercayaan animisme dan dinamisme juga membenarkan bahwa sultan adalah pemegang kuasa yang menjadi perantara antara manusia dengan Tuhan.

Secara politik, mitos Tujuh Putri yang diciptakan pada masa pemerintahan Sultan Muhammad Arsyad (1852-1869) merupakan strategi untuk mempertahankan kekuasaannya ketika rempah-rempah (cengkeh) tidak lagi menjadi sumber ekonominya. Ketika itu, pemerintah Hindia Belanda memegang kendali monopoli dengan melakukan kebijakan extirpatie ${ }^{9}$ dan hongitochten ${ }^{10}$ secara ketat dan sistematis

\footnotetext{
${ }^{9}$ Extirpatie merupakan perwujudan dari sistem monopoli rempah-rempah Hindia Belanda di Maluku Utara. Sejak awal abad 17 telah tercapai kesepakatan antara para sultan Ternate degan pihak VOC yang menjadi dasar bagi VOC untuk menebang semua pohon pala dan
} 
guna mengendalikan harga cengkeh di tingkat internasional. Sistem eksploitasi komoditi dengan cara paksa tersebut mengubah wajah Ternate sebagai pengekspor rempah-rempah menjadi daerah penyerahan wajib rempah-rempah. Pada saat yang sama, sultan Ternate tidak lagi menjadikan rempah-rempah sebagai sumber ekonominya. Sepinya perdagangan rempah-rempah, membuat sepi pula gaung kekuasaan politik para sultan Ternate. ${ }^{11}$ Implikasi yang ditimbulkannya, sultan tidak lagi menjadikan cengkeh sebagai pusat rujukan identitas diri.

Kesimpulan di atas memang spekulatif. Tetapi kenyataannya, pada periode tersebut, kekuasaan para sultan tunduk pada hegomoni ekonomi dan politik pemerintah Hindia Belanda sebagai konsekuensi dari perjanjian-perjanjian yang telah mereka buat. ${ }^{12}$ Akibat lainnya demi mempertahankan kedudukannya para sultan menjadikan agama sebagai sumber kekuatan baru. Mitos Tujuh Putri kemudian digunakan para sultan untuk membenarkan kedudukannya melalui

cengkeh di wilayah kerajaan Ternate, sehingga produksi perdagangan rempah-rempah dihalangi. Djoko Suryo, et al. hlm. 117.

${ }^{10}$ Hongitochten adalah satuan ekspedisi atau patrol bersenjata yang beroperasi secara rutin mengawasi kawasan perkebunan rempah-rempah yang tersebar di Kepulauan Maluku.Satuan ini tidak sagan-sagan mempergunakan kekuatan kekerasan bersenjata untuk menghukum siapa saja yang sengaja melanggar ketentuan atau melakukan penebangan secara sistemtis untuk bisa mengendalikan tingkat laju produksinya sampai seperempat dari jumlah yang biasanya. Lebih jelasnya lihat R.Z. Leirissa, Halmahera Timur dan Raja Jailolo: Pergolakan Sekita laut Seram Awal Abad 19.(Jakarta: balai Pustaka, 1996).hlm. 104-105.

${ }^{11}$ Djoko Suryo, et al. op. cit., hlm. 121.

${ }^{12}$ Pada tanggal 27 Mei 1824, Gubernur Jenderal Baron van der Capellen mengunjungi Ternate dan menyepakati beberapa perjanjian dengan Sultan Ternate Muhammad Zan dan Sultan Tidore Ahmadul Mansur. Adapun isi perjanjiannya sebagai berikut. (1). Pemerintah Hindia Belanda menjalin persahabatan dengan Kesultanan Ternate dan Tidore. (2). Kesultanan Ternate dan Tidore mengakui hak gubernemen atas beberapa daerah di sebarang lautan (Buru dan Seram Timur) dan berjanji membantu gubernemen bila terjadi perang serta kawula kesultanannya tidak akan menjadi kawula atau rakyat kerajaan asing. (3). Kedua kesultanan tidak akan membuat perserikatan apapun dengan kekuasaan lain tanpa seizin gubernemen dan segala perselisihan antara keduannya atau antara kawula kesultanan keduannya akan dilaporkan ke gubernemen. (4). Kedua kesultanan mengakui hak gubernemen menempatkan pegawainnya di daerah kekuasaanya atau mendirikan bangunan perkantoran atau perumahan yang akan dipilih sendiri oleh gubernemen. (5). Orang Eropa atau bangsa Eropa lainnya, orang Cina, Makassar, atau orang asing lain, berada di bawah kewenangan gubernemen. Pihak kesultanan tidak boleh memberikan izin tempat tinggal di wilayah kesultanan tanpa izin khusus dari gubernemen. (6). Pemilik perkebunan rempahrempah wajib menjaga produk yang dihasilkannnya dan hanya boleh dijual ke gubernemen. Para sultan mewajibkan para produsen rempah-rempah untuk memelihara pohon-pohon mereka sesuai dengan petunjuk yang diberikan. Perjanjian tersebut membuat penguasa kedua kesultanan itu menjadi perpanjangan tangan dari Gubernur Belanda. Sejak saat itu, pengangkatan para sultan Ternate lebih didominasi kehendak dan pilihan Belanda. Sultan tidak lagi dipilih oleh Bobato bobato nyagimoi setufkange (dewan delapan belas) dan Gam Raha (legislatif). lebih jelasnya lihatAdnan Amal, Kepulauan Rempah-Rempah: Perjalanan Sejarah Maluku Utara 1250 - 1950. Jakarta: Gora Pustaka Indonesia, 2007 
konsep-konsep magis-religius (yang diperoleh dari dunia atas) dan menjadikan sarana agar dapat diterima, dengan menciptakan silsilah yang menghubungkan dirinya sebagai keturunan nabi untuk mengokohkan kembali kedudukannya dalam mencapai tujuan yang dikehendaki. Menurut Ibrahim Alfian, mitos yang ditulis para pujanga istana demi kepentingan dinasti yang berkuasa saat itu berfungsi memperkokoh legitimasi serta memperbesar kesaktian raja yang pada gilirannya dipandang dapat menambah kemakmuran dan kesejahtraan rakyat. ${ }^{13}$ Hingga kini, cerita Tujuh Putri ${ }^{14}$ tetap memainkan peranan menentukan dalam membenarkan dan memperokoh kekuasaan para sultan Ternate dalam hubungan dengan rakyatnya.

\section{Doktrin Jou se Ngofangare (Pemimpin dengan Rakyat)}

Kekuasaan dan legitimasi Kesultanan Ternate selain ditopang oleh mitos tujuh putri di atas, adalah penciptaan doktrin Jou se Ngofa Ngare (pemimpin dengan rakyat) yang mempunyai bobot politik yang cukup penting yang hingga kini dijadikan sebagai falsafah Kesultanan Ternate. Hal ini terjadi karena istana menjadi sumber tunggal produksi wacana pengetahuan, sistem kepercayaan, acuan sistem stratifikasi sosial, simbol status, dan gaya hidup. ${ }^{15}$

Menurut Mudaffar Syah, secara implisit kalimat Jou se Ngofa Ngare mengandung dua makna yakni; unsur pemerintahan dan agama. Dalam pemerintahan kata jou berarti engkau, mengandung arti pemimpin negara/ pemerintahan, dan kata Ngofa Ngare yang mengandung arti rakyat. Ini berarti dalam sebuah negara harus ada pemerintah dan rakyat. Hal ini kemudian dimaknai "apa yang ada pada engkau, ada pada aku dan sebaliknya apa yang ada padaku, ada juga pada engkau". Sementara dalam pengertian agama kata Jou mengandung makna Tuhan, sedangkan kata Ngofa Ngare berarti hamba. ${ }^{16}$ Dalam konsep itulah mengapa para sultan Ternate ditempatkan sebagai khalifatullah atau wakil Tuhan di dunia. Dengan kedudukannya sebagai wakil Tuhan dan memerintah berdasarkan hukum keadilan, oleh sebab itu rakyat wajib mengikutinya. Orang yang tidak mengikuti raja

\footnotetext{
${ }^{13}$ Lihat Ibrahim Alfian "Sejarah dan Permasalahan Masa Kini". Dalam pidato pengukuhan Jabatan Guru Besar di Fakultas Sastra UGM pada tanggal 12 Agustus 1985, hlm 5-6.

${ }^{14}$ Mitos Tujuh Putri ternyata bukan hanya milik Kesultanan Ternate. Versi yang sama juga tersebar di beberapa daerah di Indonesia, seperti Babad Tanah Jawi, Hikayat Aceh, sehingga membentuk cerita rakyat secara umum masyarakat di Indonesia. Hal yang sama juga ditemui di berbagai cerita rakyat, seperti Panji. Cerita Panji tidak hanya hidup di kalangan orang Melayu, Jawa, sampai Thai yang merasa terikat secara biologis, antopologis, dan politis tertentu, melainkan juga menyebar secara merata melewati batas-batas ikatan tersebut. Sejalan dengan itu, menurut Adrian Veckers, khasanah cerita Panji menunjukkan bagaimana perubahan budaya, sosial, politik, dan ekonomi dikonseptualkan. Lebih jelas lihat Andrian Vickers, Peradaban Pesisir Menuju Sejarah Budaya Asia Tenggara. (Bali: Udayana University Press, 2009).
}

${ }^{15}$ Mengenai kehidupan istana lihat Darsiti Soeratman, Kehidupan Dunia Keraton Surakarta 1830-1939. (Yogyakarta: Yayasan Untuk Indonesia, 2002).

${ }^{16}$ Mudaffar Syah, Eksistensi Kesultanan Ternate dalam Sistem Tatanegara Republik Indonesia. (Ternate:Goheba, 2009), hlm.8. 
atau menolak perintahnya berarti ia menentang kehendak Tuhan. Hal ini dapat dipahami karena salah satu sumber kekuasaan istana Ternate adalah penguasaan secara hegomonik pada level wacana kebudayaan.

Sebenarnya filosofis Jou se Ngofa Ngare merupakan nilai dasar religus yang hidup pada masyarakat Ternate jauh sebelum kedatangan agama Islam. Filosofis hidup religi ini dipakai masyarakat lokal pada usaha menelusuri asal usul kejadian tentang manusia dalam hubungannya dengan sang pencipta. Dalam perkembanganya ketika Islam menjadi agama resmi Kesultanan Ternate, maka falsafah Jou se Ngofa Ngare mengalami proses materialisasi sehingga dijadikan sebagai lambang kesultanan Ternate yang berbentuk burung berkepala dua, berbadan satu dan berhati satu yang disebut goheba dopolo romdidi (burung garuda berkepala dua). Lambang ini kemudian dimaknai dalam hubungannya dengan ajaran Islam sebagai "dua kalimat sahadat". Hal ini sebagaimana dikemukan oleh Mudaffar Syah bahwa filosofis Jou se Ngofa Ngare memeliki hubungan erat dengan dua kalimat sahadat yakni Asyhadu alla ilaha illallah adalah "Jou" dan wa asyhadu anna Muhammadarrasullah adalah "ngofangare". ${ }^{17}$ Oleh karena itu, falsafah Jou se Ngofa Ngare mengandung pengertian religi, yang melambangkan menyatunya hubungan manusia dengan Tuhannya, sebagaimana digambarkan dalam sastra lisan Ternate "gudu moju si to nunako, ri jou si to suba" (aku sudah mengenalNya, karenanya aku menyembahNya).

Doktrin Jou se Ngofa Ngare tidak hanya terbatas pada aspek agama (hubungan Tuhan dengan hamba). Dalam bidang politik, hubungan antara penguasa (Jou) dengan rakyat (Ngofa Ngare) disimbolkan dengan nasi tumpeng dimana telur adalah sultan dan kuning disamakan dengan rakyat. Atau sebagai sebuah sistem hubungan rakyat dengan penguasa dan relasi antara kepala adat dan para pembantunnya dalam sistem pemerintahan. Hubungan semacam ini juga terjadi dalam masyarakat Jawa, yang menurut Suhartono, dikenal sebagai hubungan kawula-gusti, yakni rakyat diharuskan melakukan dan menjalankan berbagai perintah dari penguasa. Hal itu membuat rakyat, mau tidak mau harus loyal kepada penguasa. ${ }^{18}$

Sultan dalam kehidupan sebagai penguasa, berhak mengambil tindakan dengan cara apa dan bagaimana saja terhadap segala isi di dalam kerajaannya, termasuk manusia. Kekuasaan besar itu membuat rakyat menjadi begitu takut pada kolano (sultan). Sultan juga memiliki hak-hak istimewa dalam politik berupa Jaib Kolano dan Iddin Kolano (hak veto). Dengan hak prerogatif yang dimilikinya secara politik, membuat sultan memiliki kekuasaan begitu besar tanpa ada batasanya. Di mata rakyat, kekuasaan itu begitu besar, sehingga mengakui sultan sebagai pemilik segala sesuatu, baik harta benda maupun manusia. Karena itu, terhadap keinginan sultan, rakyat hanya mengatakan Jou kasa ngom kage (di mana ada sultan di situlah kami). Dalam keadaan demikian, orang hanya dapat tunduk-merunduk di hadapan sultan. Kalau berbicara, rakyat menyembah dulu dan mengatakan kata sembahan Jou

\footnotetext{
${ }_{17}$ Mudaffar Syah, " Filosofis Maluku Utara” dalam, Ternate Bandar Jalur Sutera. (Ternate: LInTas, 2001), hlm 87.

${ }^{18}$ Suhartono W. Pranoto, Serpihan Budaya Feodal. (Yogyakarta: Agastya Media, 2001), hlm. 110.
} 
Suba (minta permisi), setelah itu baru mengatakan apa hajatnya. Berkali-kali ia berbicara, berarti berkali-kali ia harus menyembah dan mengatakan kata sembahan Jou Suba. Hal tersebut sebagaimana tertuang dalam sastra lisan Ternate "Dara to Lefo Mapila Soro Gudu to Nunako. Gudu Moju si to Suba, ri Jou Si to Nunako"(Burung merpati kuberi tanda pada sayapnya terbang jauh kukenali. Dari jauh ku menyembahNya karena aku sudah mengenal-Nya). Pada tataran inilah sebagai contoh bagaimana kekuasaan yang dimiliki oleh oleh para sultan bukan hanya berasal dari apa yang mereka percayai, tetapi berasal dari kemampuan untuk menjadikan apa yang dipercayai sebagai acuan kepercayaan dalam masyarakat. Pada tataran inilah falsafah Jou se Ngofa Ngare menjadi sumber legitimasi kekuasaan Sultan.

\section{Gelar dan Benda Pusaka}

Para sultan Ternate memang selalu terlibat dalam usaha-usaha untuk mengukuhkan diri dengan menggunakan simbol-simbol dalam mitos Tujuh Putri. Salah satunya adalah menggunakan gelar Alam ma Kolano (penguasa dunia). Dengan menyandang gelar Alam ma Kolano dan Kolano Maluku (penguasa Maluku), sultan Ternate dianggap terkuat dan terpandang di antara raja-raja Maluku di Utara. Penggunaan gelar tersebut dapat ditemukan dalam berbagai dokumen bangsabangsa Eropa. Salah satunya, C. Bossher, yang menulis bahwa Belanda menyebut sultan Ternate sebagai 'penguasa Maluku'. Bahkan sultan Ternate sendiri melalui dokumen Belanda dari abad 19 menyebut diri sebagai 'penguasa Maluku' dan 'sultan Maluku'. C. Bossher menulis;

“Raja Ternate biasanya disebut sebagai Alam ma Kolano (penguasa dunia), dan Kolano Maluku (penguasa Maluku) yang membawa pada kekuatan dan kekayaannya. Raja Tidoor (Tidore) biasa disebut Kie ma Kolano (raja gunung). Bacan secara khusus dikenal dengan nama Kolano Madehe atau sama dengan raja pintu keluar atau ujung. Jailolo secara khusus disebut sebagai Jiko ma Kolano atau raja pelabuhan karena istana berada di Pelabuhan Jailolo". ${ }^{19}$

Dengan menyandang gelar Alam ma Kolano, para Sultan Ternate memandang kekuasaan sebagai suatu ketunggalan, utuh, dan bulat. Maksudnya, kekuasaan itu tidak boleh bersaing, terkotak-kotak atau terbagi-bagi. Oleh sebab itu, dengan menyandang gelar Alam ma Kolano (penguasa dunia), maka tiap raja yang memerintah berkewajiban mengemban misi memperkuat dinasti. Mereka percaya bahwa apabila kekuasaanya berhasil, maka sekaligus dapat memperkuat kedudukannya dalam kerajaannya.

Sejalan dengan itu, dalam buku adat raja-raja Ternate (buku tembaga), menyebutkan bahwa sultan Ternate bergelar Alam ma Kolano mempunyai kesaktian dan memiliki berkat yang mendatangkan keselamatan maupun kebahagian. Kemampuan ini dipercaya sebagai anugerah dari Tuhan, sehingga pada konsep

\footnotetext{
${ }^{19}$ A.B. Lapian, dalam pengantar Memorie van Overgave J.H. Tobias 1857- Memorie van Overgave C. Bosscher Residen Ternate 1859, (Jakarta: ANRI, 1980), hlm. 53.
} 
inilah kekuasaan para sultan tidak dapat dipisahkan atau selalu dihubungkan dengan konsep spiritual yang berhubungan dengan kepercayaan adanya kesejajaran antara jagad raya dan dunia manusia. Hal ini sejalan dengan konsep kekuasaan Jawa yang menempatkan raja sebagai penguasa tunggal di bidang kekuasaan fisik maupun spiritual (raja sebagai sentral yang memancar ke alam makrokosmos dan mikrokosmos). ${ }^{20}$ Itulah mengapa kemudian para sultan Ternate ditempatkan sebagai khalifatullah atau wakil Tuhan di dunia. Pada tataran inilah, menurut Djoko Suryo, agama menjadi sumber legitimasi sekaligus sumberdaya politik atau sarana kekuasaan. $^{21}$

Dalam struktur politik kesultanan Ternate, sultan adalah titik pusat kekuasaan. Sebagai puncak hierarki, sultan memegang kekuasaan yang besar. Hal itu tercermin dari kepemilikannya terhadap benda-benda pusaka, gelar, ataupun silsilah geonologis. Salah satu benda pusaka yang dipercaya memiliki nilai magis adalah stampa (mahakota) ${ }^{22}$ Kesultanan Ternate yang dipercayai berasal dari kayangan. Mahakota ini diyakini berasal dari 'dunia atas' dan menjadi mu'jizat bagi sultan dalam kepemimpinannya dari masa ke masa. Hal ini diceritakan dalam mitos Tujuh Putri berikut:

"Setelah Mansur Malamo genap berusia setahun, mereka berpamit untuk kembali ke bumi. Tapi rencana itu selalu tertunda gara-gara Malamo selalu menangis setiap hendak berangkat. Penguasa Nirwana berkata ia akan aman dengan tutup kepala saya. Mansur Malamo baru diam setelah kakeknya memberinya stampa (mahkota) yang tengah dikenakannya." 23

\footnotetext{
${ }^{20}$ Soemarsaid Moertono, Negara dan Usaha Binna Negara di Jawa Masa Lampau: Studi Tentang Mataram II Abad ke XVI Sampai XIX. (Jakarta: Yayasan Obor Indonesia, 1985), hlm. 32-33.

${ }^{21}$ Djoko Suryo, et al., op. cit., hlm. 102-107.

22 Mahakota (stampa) berambut panjang terurai kebelakang, dililit dengan perak dan berbentuk topi. Mahkota ini dihiasi batu-batuan permata kurang lebih seratus buah, yang terdiri dari perunggu, perak, mutiara, emas, berlian, akik, shafier, dan jamrud, yang dilekatkan di samping kiri kanan dan bagian depan. Mahkota diletakkan pada sepotong kayu yang dibuat khusus, yang disebut kalbu. Setiap tahun dalam tradisi kesultanan Ternate, bila datang Hari Raya Idul Adha (Hari Raya Haji), maka dilakukan pemotongan rambut mahakota. Mahakota dipakai oleh sultan dalam kegiatan yang berhubungan dengan penobatan sultan yang baru. Upacara pelantikan sultan biasanya disebut upacara kabasarang kolano, di mana sultan didudukkan di kursi kerajaan. Selanjutnya, Kimalaha Marsaoli sebagai Ketua Dewan Delapan Belas atau legislatif (bobato nyagimoi se tofkange) mengangkat mahkota dari kalbunya dan melatakkan di kepala sultan diiringi doa semoga mendapat ridha Allah SWT. Satu hal manarik yang diyakini masyarakat Ternate adalah bila akan datang musibah, penyakit, peperangan, dan keonaran yang menimpa Pulau Ternate, maka posisi mahkota akan kembali ke keadaan aslinya dan rambut mahkota berdiri seperti seekor ayam jantan sedang berkelahi. Lihat L. Radjiloen. Dataran Tinggi Foramadiahi adalah Ternate Awal Ke Dataran Rendah Limau Jore-jore Sebagai Ternate Akhir, Ternate: Depdikbud, 1982.
}

${ }^{23} \mathrm{P}$ van der Crab, op. cit., hlm. 12. 
Selain mahakota, benda pusaka lain yang dianggap sebagai benda-benda keramat dan sakti adalah kursi kerajaan, payung kerajaan, tongkat kerajaan dari rotan kembar berkepala gading, bedil emas, pedang beraneka bentuk, lampu kristal besar bercabang enam melengkung dengan tiga mata lampu, baju tembaga, perisai, meriam kecil dan sedang, serta lambang kerajaan Goheba ma Dopolo Romdidi (burung garuda berkepala dua). ${ }^{24}$ Benda-benda tersebut sampai sekarang dipercayai masyarakat sebagai sumber kemakmuran.

\section{Gambar 1. Mahkota Kesultanan Ternate}

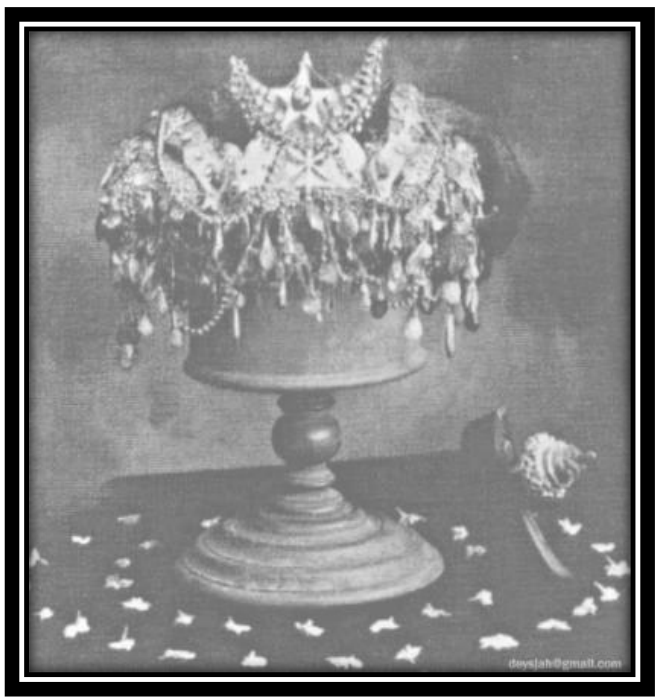

Sumber: http://www.indonesia-heritage.net/2014/09/mahkota-ajaib-di-istana-ternate/

Sudah menjadi pengetahuan umum bahwa Kesultanan Ternate adalah dinasti yang berasal dari keturunan para nabi dari kayangan. Sebab itulah dia bergelar sebagai Alam ma Kolano (penguasa alam). Walaupun sultan menjadi pemimpin kerajaan, namun gelar tertinggi bukan hanya sultan, tetapi juga kolano, karena hanya kolano yang dapat mengeluarkan iddin (hak veto) yang dipatuhi masyarakat. Oleh karena itu, pada diri seorang sultan terdapat dua gelar kebangsawanan, yakni kolano dan sultan. Menurut Djoko Suryo posisi kolano hingga saat ini tetap dipergunakan sebagai instrumen pengendalian dan pengelolaan politik dalam negeri. Sementara posisi sultan lebih banyak diarahkan pada kepentingan-kepentingan hubungan internasional. ${ }^{25}$

Sejalan dengan itu, untuk memperkokoh kedudukan sultan sebagai kelas penguasa, para sultan menggunakan nama dan gelar dari Arab dan Persia. Seperti gelar yang digunakan oleh Sultan Ternate ke-41 Muhammad Ayanhar (1876-1856), dengan bergelar Asultan Tadjul Mahful Binajatilahi Lhanan Sirajul Mulki Amirudin Iskandar Munawarusadik Wahoewaminaladdin Syah Putra Ajanhar Raja Ternate

\footnotetext{
${ }^{24}$ Lebih jelasnya lihat Syahril Muhammad, Kesultanan Ternate: Sejarah Sosial Ekonomi EPolitik. (Yogyakarta: Ombak; 2006), hlm. 72.
}

${ }^{25}$ Djoko Suryo, et al. hlm.121-122. 
serta penambahan gelar "Syah" (gelar para raja-raja Persia) di belakang nama seorang sultan, suatu gelar yang digunakan para sultan Ternate sejak abad 19 hingga sekarang. ${ }^{26}$

Tujuan penggunaan gelar-gelar tersebut adalah untuk merebut pengaruh massa (efek sosial), yang menurut Sartono Kartodirdjo, digunakan untuk membangun kekuasaan dinasti agar tetap lestari. ${ }^{27}$ Oleh karena itu, setiap sultan Ternate yang memerintah merasa berkewajiban mengemban misi untuk memperkuat dan mempertahankan kekuasaan dinastinya. Apabila ia berhasil melakukannya, maka ia sekaligus memperkuat kedudukannya sendiri di dalam dinasti tersebut.

\section{Kadaton (Istana): Pusat Magis-Religius}

"Gedung ini adalah tempat orang-orang tertinggi dan termulia, yaitu tempat bersemayamnya sultan-sultan yang digelarkan di atas pundaknya beliau-beliau itu "sirajul gulub" cahaya hati. Sultan-sultan Islam yang digelarkan menurut adat Iskandar Zulkarnain keturunan sultan-sultan yang adil bahkan saleh. Yaitu Sultan Muhammad Ali ibnu Sultan Sirajurrahman beserta menteri-menteri dan semua orang besar bermusyawarah mencari satu tempat yang layak untuk mendirikan kadaton(istana) sebagai tanda kenang-kenangan bagi keturunan beliau yang menjadi sultan pada akhir zaman. Dengan kodrat Allah Azza wa Jallah terkabullah cita-cita beliau maka kadaton Sultan Ternate dibangun di atas sebuah bukit. Dengan takdir Allah, terpancarlah sebuah mata air di bawah kaki bukit tersebut dan sampai sekarang terkenal dengan nama "air sentosa" air inilah tempat beliau mandi dan mengambil air wudhu. Sedang beliau duduk lalu berwasiat kepada segenap menteri dan rakyat bahwa barang siapa yang mendiami kadaton ini, sebagai amanat Allah SWT bahwa yang menjadi sultan harus mentaati: "amar ma'ruf nahi munkar, salat, puasa, kasihi fakir miskin, dan semua rakyat" bahwa yang menjadi sultan dan mendiami kadaton ini dengan tidak menepati wasiat tersebut, maka tidak akan selamat dunia dan akhirat lam yalid sala'matan fiddunya wal-akhirat". Semoga yang mendiaminya agar dapat mentaati wasiat dimaksud"wadumtum shalimien fi hifdhil wasiah minassulta'nil - amien.-

Permulaan tiga puluh hari zulkaidah hijratun nabi dua ratus dua puluh tatkala ini rumah dari pada bulan hari ahad seribu dua ratus delapan tahun." 28

Kutipan di atas merupakan isi prasasti kadaton Ternate yang dibuat pada masa pemerintahan SultanTernate ke 41 Muhammad Ali (1801-1807). Isi prasasti di

\footnotetext{
${ }^{26}$ Mengenai pengaruh Islam terhadap struktur pemerintahan Kesultanan Ternate, lihat Shaleh A. Putuhena, Struktur Pemerintahan Kesultanan Ternate dan Agama Islam. (Jakarta: Leknas LIPI, 1987), dan Djoko Suryo, et al. Agama dan Perubahan Sosial Studi: Tentang Hubungan Antara Islam, Masyarakat, dan Struktur Sosial Politik Indonesia. (Yogyakata: UGM LKPSM. 2001).

${ }^{27}$ Sartono Kartodirdjo, Kepemimpinan dalam Dimensi Sosial. (Jakarta:LP3, 1984), hlm. 230.

${ }_{28}$ Prasasti Ternate dikutip dari Tabloid Parada, edisi 8, 3-16 Juni 2000, hlm. 7.
} 
atas menggambarkan bahwa dalam membangun basis kekuasaanya, para sultan Ternate membuat istana memiliki doktrin pusat anutan magis-religius. Hal itu dapat dilihat dari kalimat yang menyebutkan bahwa yang berhak mendiami kadaton adalah orang-orang tertinggi dan termulia "sirajul gulub" untuk menjaga dan menyebarkan agama Islam.

Doktrin kekuasan tersebut dijadikan pembenaran bahwa sumber kewenangan yang diperoleh para Sultan Ternate dalam memerintah berasal dari sumber yang diangggap suci, yakni Tuhan. Kepercayaan dan agama menguasai masyarakat Ternate dan kedudukan sultan dalam masyarakat memperoleh dukungan yang kuat dari keyakinan agama. Alasan inilah yang membentuk pemikiran bahwa hanya orang-orang anggota keturunan sultanlah yang mempunyai hak untuk tetap berkuasa. Legitimasi magis-religius tersebut menyebabkan kadaton bukan semata-mata tempat tinggal raja dan kerabatnya, melainkan juga dipandang sebagai negara itu sendiri. Menurut AA GN Ari Dwipayana, istana dalam sejarah perkembangannya, menjadi institusi kekuasaan yang secara politik mempunyai bobot yang sama dengan institusi kebangsawanan itu sendiri. ${ }^{29}$

Sebagai pusat anutan, sultan dan keluargannya merupakan komunitas yang mempunyai ruang hidup sendiri. Ruang hidup para sultan dalam Kesultanan Ternate adalah kadaton, ${ }^{30}$ yang sejak kelahirannya ditata menurut adat-istiadat, agama, dan kepercayaan tertentu. Kadaton memiliki luas 44.560 M2. Kompleks kadaton meliputi;Kadaton, Sigi Lamo (masjid sultan), Ngara Opas (pintu gerbang istana), Ngara Lamo (gedung pertemuan dewan kerajaan), Ake Santosa (tempat mandi dan wudhu), alun-alun Kadaton, Dodoku Mari (pelabuhan sultan dan makam raja-raja Ternate yang berbatasan dengan masjid sultan. ${ }^{31}$

Kadaton Ternate didirikan pada masa pemerintahan Sultan Muhammad Ali, di desain memiliki makna filosofis dan spiritual (magis). Konstruksi bangunan tradisional berlantai dua menghadap ke arah laut memiliki beragam nilai; pertama, bentuk istana mengambarkan seekor singa yang sedang duduk dengan dua kaki depannya menopang kepalanya, diibaratkan "berbentuk tubuh manusia" yang sedang bersila. Mengandung makna siapa yang menjadi Sultan siap-sedia melaksanakan pengabdiannya pada agama, bangsa, dan negara. Kedua, memasuki

\footnotetext{
${ }^{29}$ Untuk lebih jelasnya dalam melihat kemampuan bangsawan dalam mengelola kekuasaan politiknya, baca AA GN Ari Dwipayana, Bangsawan dan Kuasa Kembalinya Para Ningrat di Dua Kota. (Yogyakarta, IRE Press, 2004), hlm. 32.

${ }^{30}$ Kadaton merupakan istilah yang mempunyai beberapa arti. Pertama, berarti negara atau kerajaan.Kedua, merupakan tempat tinggal raja bersama keluarga dan abdi dalemnya. Kadaton juga digunakan untuk menerima tamu resmi serta untuk tempat kegiatan atau upacara resmi. Dalam kadaton terdapat banyak ruang untuk tempat berkerja sebagian abdi dalem dan juga untuk menyimpan barang-barang milik raja. Menurut Darsiti Soeratman, istana merupakan bangunan yang unik, disebabkan ukurannya yang paling luas dan struktur bangunan yang khusus, dan dimonopoli oleh raja. Dalam penjelasan ini, agar tidak mengalami kejenujan, penulis menggantikan kadaton dengan kata istana, yang secara secara substansial memeliki makna yang sama, yaitu tempat tinggalnya para reja dan kerabatnya. Untuk lebih jelasnya lihat Darsiti Soeratman, op cit., hlm. 64-68.
}

${ }^{31}$ Radjiloen L. op. cit.,, hlm. 72-73. 
kadaton dari depan melalui dua buah tangga dengan 27 buah anak tangga. Makna 27 buah anak tangga itu mengandung arti 27 malam pada bulan Ramadhan (lailatul qadar) dan 27 Rajab (Isra dan Maraj Nabi Muhammad SAW). Ketiga, tinggi bangunan kadaton dari dasar sampai kebubungan setinggi 17 meter. Secara filosofis berhubungan dengan jumlah bilangan rakaat dalam sholat lima waktu (Shubuh, Dhohor, Ashar, Magrib dan Isya) yang semuanya berjumlah 17 rakaat. Disamping itu angka 17 dihubungkan dengan tanggal 17 bulan ramadhan yakni peristiwa nuzulul Qur'an.

\section{Gambar 2. Istana Kesultanan Ternate}

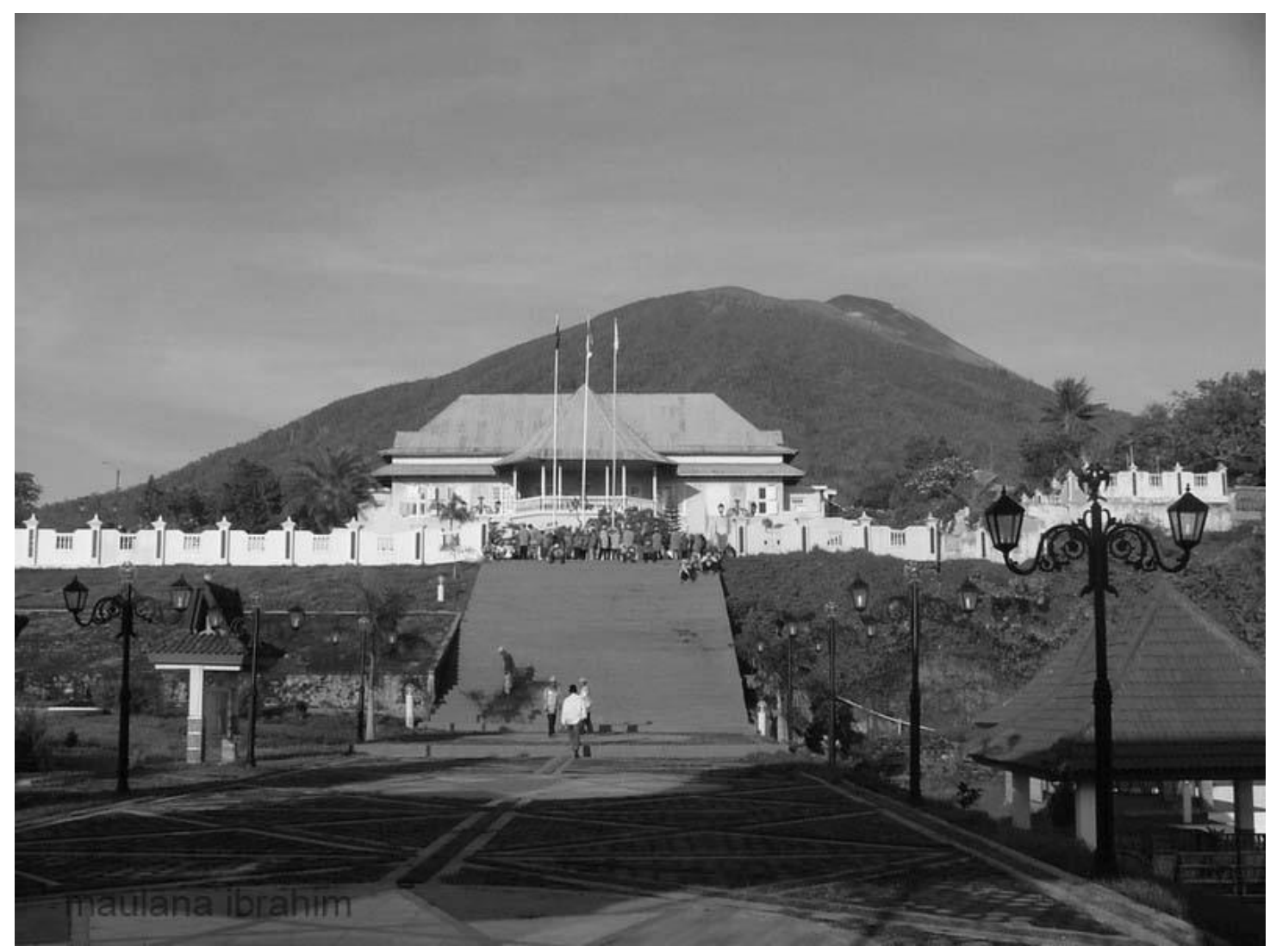

Sumber: https://www.goodnewsfromindonesia.id/2014/06/26/terima-kasih-ternate

Keempat, di dalam bangunan kadaton, sultan memiliki ruangan tersendiri yang terletak di bagian utara dan selatan. Ruangan sebelah utara terdapat ruangan ibadah sultan (kamar puji). Fungsinya sebagai tempat ibadah sultan, di ruangan ini juga terdapat sebuah meja marmar berbentuk bundar, di atasnya diletakkan sebuah Qur'an pusaka dan keris pusaka. Wanita dilarang memasuki ruangan ini dan dianggap sebagai tempat yang paling keramat. Ruangan ini digunakan tempat ibadah oleh sultan, seorang yang diyakini sebagai perantara tunggal antara mikrokosmos dan makrokosmos. Kelima, Di sudut bangunan dan pintu utama menuju kadaton ditempatkan replika binatang singa, macan, ular, dan lipan. Yang memeliki makna bahwa dalam bidang pemerintahan, sultan harus disegani dan 
dikagumi oleh kawan maupun lawan. Disamping itu, sultan juga selalu waspada dan siap siaga dalam menghadapi setiap musuh, sehingga dapat menjaga keutuhan dan keselamatan masyarakat di walayah kekuasaanya. Sementara itu, di halaman utama (taman) kadaton ditanami pohon beringin. Pohon ini memberi makna bahwa sebagai pemimpin, sultan harus menaungi dan memberi kesejukan seluruh masyarakat di wilayah kekuasaanya. Dan untuk memasuki istana, harus melewati pintu gerbang utama yang disebut ngara opas yang selalu dikawal 13 prajurit istana. ${ }^{32}$ Elemen-elemen tersebut merupakan satu kesatuan yang tidak bisa dipisahkan satu sama lain karena keberadaannya saling mengikat dan dianggap sebagai tempat yang keramat, sebagaimana tampak pada gambar 2 .

Pengaturan bangunan kadaton dengan berbagai macam klasifikasi yang penuh makna filosofis dan religi tersebut, menunjukan adanya upaya untuk menjadikan istana sebagai pusat panutan. Dalam hal ini, kekuasaan yang dimiliki sultan Ternate adalah suatu yang utuh dan tunggal. Maksudnya, kekuasaan itu tidak boleh bersaing, menyeluruh, dan tidak terkotak-kotak atau terbagi-bagi. ${ }^{33}$ Kadaton Ternate sebagai pusat kosmos dianggap tempat yang keramat, hingga kini diyakni masyarakat berasal dari "dunia atas" sebagaimana diceritakan dalam mitos Tujuh Putri. Pengaturan bangunan ini juga sama dalam pemikiran Jawa, yang menurut Darsiti Soeratman, pola pengaturan bangunan di dalam istana itu tidak terlepas dari usaha raja untuk menyelaraskan kehidupan warga masyarakat atau komunitas istana dengan jagad raya. Dengan demikian, istana merupakan lambang penuh arti dan pusat magis. ${ }^{34}$ Dengan demikian sejak kelahirannya kadaton telah ditata menurut filosofis kekuasaan pusat anutan, dimana kadaton bukan hanya tempat tinggal tinggal Sultan dan kerabatnya melainkan dipandang sebagai negara itu sendiri.

Perwujudan sebagai pusat panutan juga nampak dari kemegahan upacaraupacara yang diselengarakan di kadaton, seperti acara penobatan sultan baru (jou kolano), hari ulang tahun sultan (legu gam), dan upacara kematian sultan. Upacaraupacara tersebut menjadi kriteria status sosial yang melambagkan kekuasaan, kekayaan, dan kewibawaan sultan. Selain itu, dalam kehidupan kadaton, keluarga sultan dan bangsawan mempunyai gaya hidup sendiri, terikat oleh nilai-nilai tertentu. Seperti dalam hal aturan pakaian yang diberlakukan di dalam istana, misalnya warna putih hanya dipakai oleh sultan, warna kuning untuk para bangsawan (bobato dunia) yang berasal dari marga Soa-sio dan Sangaji. Warna hitam untuk para imam (bobato akhirat), warna merah untuk para prajurit dari marga Soa, Heku, dan Cim. ${ }^{35}$ Sementara bagi masyarakat biasa, untuk masuk ke kadaton harus melepaskan sandal, barang-barang yang di bawa di atas kepala harus diturunkan. Begitu pula dalam hal berbicara dan bersikap sesuai dengan tata karma seperti menyembah, (suba), duduk bersila bagi pria, bersimpuh bagi wanita, dan

${ }^{32}$ Ibid, hlm. 75-76.

${ }^{33}$ B.Soelarto, Sekitar Tradisi Ternate, (Jakarta: Proyek Pengembangan Media Kebudayaan Departemen Pendidikan Kebudayaan RI, 1982), hlm. 5-7.

${ }^{34}$ Darsiti Soeratman, op. cit., hlm. 121.

${ }^{35}$ Radjiloen L. op. cit., hlm. 56-57. 
membungkukkan badan. Menurut Soemarsaid Moertono peraturan-peraturan istana itu sengaja dibuat untuk memuliakan sekaligus mengokohkan legitimasi raja dan institusinya. ${ }^{36}$

Selain beberapa sumber kekuasaan di atas, penguasaan atas tanah juga merupakan salah satu elemen kekuasaan Kesultanan Ternata. Tanah dalam Kesultanan Ternate mengenal tiga tingkatan kepemilikan. Masing-masing tanah sultan (aha kolano), tanah bangsawan (aha soa), dan tanah masyarakat (kaha cacu). Ketiganya mempunyai kedudukan dan fungsi yang berbeda-beda. ${ }^{37}$ Aha kolano hanya diperuntukkan bagi sultan dan keluargannya. Hingga kini, sultan memiliki monopoli sejumlah tanah di wilayah kekuasaanya. Hak penguasaan tanah tersebut seperti; aha kolano dan aha cocatu (kebun sultan) bersifat tetap..$^{38}$ Tanah memang menjadi barang yang menentukan status dan peran di dalam masyarakat feodal, suatu hal yang kemudian membuat sultan mempunyai kedudukan kuat di masyarakat. Penguasaan atas tanah memunculkan kekayaan, kekuasaan, dan pengikut.

Bagi masyarakat Ternate, sultan adalah pemilik alam dan isinya. Masyarakat petani juga menyadari bahwa mereka merupakan bagian integral dari kehidupan kerajaan dan sultan sebagai pusat penggerak seluruh kehidupan. Sistem feodalisme yang dianut Kesultanan Ternate menempatkan sultan sebagai pemilik tanah kerajaan. Sultan menjadi pemegang kekuasaan tertinggi dan kekayaan terbanyak. Ini menjadi alasan politik mengapa Sultan Ternate ke 47 Iskandar Muhammad Djabir Sjah (1929-1975), menolak permintaan Soekarno untuk menandatangani surat pernyataan pengabungan Kesultanan Ternate ke dalam NKRI. Sultan Djabir Sjah mengatakan, "Dalam segi tata pengelolaan atas segala sumber daya alam telah diatur secara sempurna dalam hukum adat kesultanan dan masyarakatnya, sehingga tidak boleh dikuasai oleh negara. Karena yang demikian akan menghilangkan sistem nilai lokal yang diwariskan oleh para leluhur dan diyakini sebagai amanah dari Tuhan untuk dijaga dan lestarikan." ${ }^{39}$

\section{Kesimpulan}

Sebagai salah satu kekuasaan tradisional yang masih tetap hidup hingga saat ini, keberadaan Sultan Ternate tidak pernah kehilangan legitimasi politiknya, sehingga memiliki posisi politik sebagai pusat anutan di dalam kehidupan

\footnotetext{
36 Soemarsaid Moertono, op. cit., hlm. 142.

${ }^{37}$ Selain kepemilikan tanah yang bersifat tetap, dikenal pula hak atas tanah sultan yang bersifat sementara yang disebut hak tolagumi, hak safa, hak ruba bangga, dan hak jurami. Tanahtanah tersebut merupakan tanah sultan yang diberikan ke birokrat kerajaan dan keluargannya yang telah membantu sultan dalam menjalankan pemerintahannya. Selain diberikan ke para pejabat kerajaan, tanah tersebut juga diberikan ke Kepala Soa (kimalaha) atau marga untuk kepentingan marga itu yang disebut kaha soa. Tanah-tanah tersebut dilarang dijual atau dipindah-tangankan ke marga lainnya.
}

${ }^{38}$ Syahril Muhammad, op,cit., hlm. 13-14.

${ }^{39}$ Mudaffar Syah, op, cit., hlm.13. 
masyarakat Ternate. Dalam struktur politik pemerintahan Kesultanan Ternate, sultan adalah titik pusat kekuasaan. Sebagai puncak hirarki, Sultan memiliki kekuasaan yang besar. Hal itu tercermin dengan adanya berbagi atribut, seperti; benda-banda pusaka, gelar, ataupun mitos-mitos genealogi yang kesemuanya berfungsi untuk mengabsahkan kedudukan sultan sebagai penguasa.

Dalam membangun basis kekuasannya, setidaknya terdapat dua strategi yang dipakai sebagai upaya membentuk dan memperkokoh kedudukannya. Pertama, strategi magis keagamaan. Sultan sebagai puncak piramida kekuasaan dalam menjalankan pemerintahnnya didampingi para bobato (dewan menteri), yaitu bobato dunia (pejabat kesultanan yang membidangi pemerintahan) dan bobato akhirat (pejabat pejabat kesultanan yang mengurusi masalah-masalah keagamaan). Dalam bidang keagamaan (bobato akhirat) di Kesultanan Ternate, sultan adalah pemimpin tertinggi atau imam agung. Sebagai imam agung, sultan berkewajiban menjaga, melindungi, menyebarkan dan melestarikan agama Islam. Pada konteks ini, para sultan di Ternate menyebut dirinya sebagai kalifatullah karena memiliki dua macam hak prerogatif (hak veto) yaitu Idhin Kolano dan Jaib Kolano.

Kedua, arena kebudayaan. Perwujudan sebagai pusat anutan istana tetap mempertahangkan upacara-upacara tradisional istana seperti Kololi Kie (ritual mengelilingi pulau), dan Fere Kie (ritual mendaki gunung). Ritus-ritus istana ini tetap dijalangkan karena merupakan sumber legitimasi kultural bahwa istana masih mempunyai daya magis, sakral dan simbol kewibawaan. Selain itu, merancang upacara-upacara yang mempunyai bobot politik seperti legu gam (perayaan hari ulang tahun sultan), dan membangun jaringan kekerabatan (politik kekerabatan) dengan memberikan gelar kehormatan pada pejabat atau mantan pejabat baik pusat maupun daerah. Setidaknya strategi kebudayaan sebagai titik masuk (entry point) untuk menjadikan istana sebagai pusat pengemban, pelestarian, dan pengembangan kebudayaan Ternate.

Sebagai sebuah realitas sejarah, kemampuan bertahan para Sultan Ternate dalam panggung politik lokal hingga kini, banyak di pengaruhi oleh kepercayaan masyarakat bahwa kelompok bangsawanlah yang berhak memerintah yang diperoleh lewat legitimasi geanologis (mitos tujuh putri). Legitimasi ini di sosialisasikan secara terus menerus ini, yang pada gilirannya menghasilkan suatu kepercayaan masyarakat Ternate tentang kelebihan dan keistimewaan para sultan, sehingga melahirkan rasa patuh dan kehadiraanya dapat memberi ketentraman dan kesejahtaraan masyarakat. Reproduksi symbol dan makna atas mitos dan religi telah menjadi sebagian pengikat efektif relasi antara sultan dengan rakyat Ternate.

\section{Daftar Pustaka}

Amal, Adnan Kepulauan Rempah-Rempah: Perjalanan Sejarah Maluku Utara 1250 - 1950. Jakarta: Gora Pustaka Indonesia, 2007.

Lapian, A.B. dalam pengantar Memorie van Overgave J.H. Tobias (1857)- Memorie van Overgave C. Bosscher Residen Ternate (1859), Jakarta: ANRI, 1980. 
Dinsie Anas \& Rinto Taib, Ternate Sejarah, Kebudayaan \& Pembangunan Pedamaian Maluku Utara. Ternate: LeKRa-MKR, 2010.

Dwipayana, AA GN Ari, Bangsawan dan Kuasa Kembalinya Para Ningrat di Dua Kota. Yogyakarta, IRE Press, 2004.

Vickers, Andrian, Peradaban Pesisir Menuju Sejarah Budaya Asia Tenggara. Bali: Udayana University Press, 2009.

Anderson, Benedict R. O'G. Kuasa-Kata: Jelajah Budaya-Budaya Politik di Indonesia. Yogyakarta: Mata Bangsa, 2000.

Soelarto, B. Sekitar Tradisi Ternate, Jakarta: Proyek Pengembangan Media Kebudayaan Departemen Pendidikan Kebudayaan RI, 1982.

Geertz, Clifford. Abangan, Santri, Priyayi dalam Masyarakat Jawa. Jakarta: Pustaka Jaya, 1981.

Djoko Suryo, et al. Agama dan Perubahan Sosial Studi: Tentang Hubungan Antara Islam, Masyarakat, dan Struktur Sosial Politik Indonesia. Yogyakata: UGM LKPSM. 2001.

Soeratman, Darsiti. (Kehidupan Dunia Keraton Surakarta 1830-1939. Yogyakarta: Yayasan Untuk Indonesia, 2002.

Clercq, F.S.A. de Ternate: Karesidenan dan Kesultanan, terjemahan Noer Fitriyanti dari Bijdragen tot de Kennis der Residentie Ternate, 1890. Ternate: Komunitas Uma Sania, 2007.

Moedjanto, G. Konsep kekuasaan Jawa: Penerapannya Oleh Raja-raja Mataram. (Yogyakarta: Kanisius, 1987).

Alfian, Ibrahim et.al. Dari Babad Hikayat sampai Sejarah Kritis. Yogyakarta: Gadjah Mada University Press, 1992.

Syah, Mudaffar. Eksistensi Kesultanan Ternate dalam Sistem Tatanegara Republik Indonesia. Ternate: Goheba, 2009.

Crab, P van der. Geschiedenis van Ternate, in Ternataansche en Maleische Teks, Beschreven Door den Ternataan Naidah, Met Vertaling en Aantekeninghen Door, BKI, jilid 26, nomor 2.

Radjiloen, L. Dataran Tinggi Foramadiahi adalah Ternate Awal Ke Dataran Rendah Limau Jore-jore Sebagai Ternate Akhir.Ternate: Depdikbud, 1982.

Moertono, Soemarsaid. Negara dan Usaha Binna Negara di Jawa Masa Lampau: Studi Tentang Mataram II Abad ke XVI Sampai XIX. Jakarta: Yayasan Obor Indonesia, 1985.

Kartodirdjo, Sartono. Kepemimpinan dalam Dimensi Sosial. Jakarta: LP3, 1984.

Pranoto, Suhartono W. Serpihan Budaya Feodal, Yogyakarta: Agastya Media, 2001. 
Putuhena, Shaleh A. Struktur Pemerintahan Kesultanan Ternate dan Agama Islam. Jakarta: Leknas LIPI, 1987.

Muhammad, Syahril. Kesultanan Ternate: Sejarah Sosial Ekonomi E Politik. Yogyakarta: Ombak; 2006.

Tabloid Parada, edisi 05, 20-05 Juni 2000. 